\title{
ECONOMÍA POLÍTICA DEL CASTIGO: DISPOSITIVOS DEL PODER Y EL CONTROL SOCIAL
}

Juan Cajas ${ }^{1}$

\section{Resumen}

Este ensayo tiene por objeto un análisis transdisciplinario de la economía política del castigo, centrando la atención en la genealogía del "saber criminológico", y los procesos de constitución de los dispositivos políticos de control social. La reflexión se nutre con el acervo teórico del derecho penal, la criminología y la antropología, entre otras disciplinas fundamentales para entender las coordenadas punitivas del mundo contemporáneo. A través de estas reconstruímos los supuestos ideológicos de la doctrina de la defensa social y, aventuramos hipotéticamente, que la estigmatización de la otredad inmigrante en Europa y Estados Unidos, tiene como soporte una reactualización de dispositivos normativos que parecían superados. Asimismo, tendemos un puente analítico entre los saberes de la criminología clásica y las reflexiones que sustentan los modernos estigmas del control social.

Palabras clave: Estigma social / control social / criminología / delito / inmigrantes

\section{PREÁMBULO}

Las culturas delimitan la conducta de sus miembros sobre la base de un catálogo de normas, exclusiones o tabúes. No obstante, al fijar los límites de la acción humana se inaugura, también, una invitación a la ruptura de los mismos. La consecuencia más inmedita es la expiación, el destierro o el castigo; éstas sanciones normalmente se encuentran asociadas a cierta idea del mal, una categoría que encontramos presente en la superficie narrativa del derecho, la criminología o la antropología, entre otras disciplinas que se ocupan del quehacer normativo, esto es, del crimen y el castigo. Para Raskolnikov, el personaje de Dostoyevski, la sociedad se divide en dos sectores: "hombres superiores" con libertad para cometer crímenes en nombre de la humanidad sin que las leyes impliquen un freno, y "hombres inferiores" cuyo deber es estar sometidos al imperio de la ley. Bajo esta perspectiva, el emigrante moderno que cruza en oleadas huyendo de sus países en guerra, ha devenido en paria, nómada inferior y peligroso y, en consecuencia, sometido a políticas actuariales de control selectivo y aislamiento, con el propósito de salvaguardar el orden social existente. Tal es la lectura que podríamos efectuar de la criminología de pensamiento único, puesta en marcha en países de Europa y en Estados Unidos, para enfrentar el fenómeno

\footnotetext{
${ }^{1}$ Doctor. Profesor de Antropología y Sociología Jurídica en el Doctorado en Derecho de la División de Estudios de Posgrado de la Facultad de Derecho de la Universidad Autónoma de Querétaro, México. E-mail: juancajas@gmail.com
} 
migratorio y la insurgencia islámica. Con base en lo anterior, efectuamos un rastreo transdisciplinario sobre el proceso de constitución del saber criminológico, con el objetivo de ubicar los referentes e interconexión entre los supuestos ideológicos, viejos y nuevos, de la doctrina de la defensa social en el mundo occidental.

\section{LA ECONOMÍA POLÍTICA DEL CASTIGO}

El saber criminológico se construyó en cercanía de otros saberes, entre éstos, la teoría política. La política, pensada como arte del buen gobierno, permea la génesis del conocimiento criminológico, ya que implica en su parte medular el control social. En su fase primigenia el saber criminológico se presenta de forma inasible; es difuso y ecléctico. Ideológicamente forma parte del artificio retórico de diversos actores sociales; justifica prácticas de dominación en variados campos de la vida social. El vocablo criminología sintetiza semánticamente una sumatoria de discursos provenientes de diversos campos disciplinares. El adjetivo criminal llegó a convertirse en una suerte de comodín o prolongación cognitiva especializada de algunas disciplinas. Surgieron así la antropología, la sociología o la psicología criminal. En esta tesitura, el estatus disciplinario del saber criminológico, no constituía un cuerpo coherente y sistematizado de conocimiento, exigencia básica de todo saber científico. Como disciplina autónoma la criminología, al igual que otras ciencias, se forja en el siglo XIX y alcanzaría la madurez en el XX. En lo general, la criminología estudia o se interesa en todo aquello que es sancionado por la ley penal o que garantiza el orden social, según afirma Massimo Pavarini.

Fragmentos del saber criminológico han sido, siempre, piezas sustanciales de la retórica del poder, sea este de origen religioso, de izquierda o de derecha. La pluralidad discursiva es desbordante. Para los críticos de este saber, el abigarramiento de ideas sobre el crimen, había generado la impresión de ser un campo de conocimiento exclusivamente técnico e intelectualmente poco serio. La razón del sincretismo o multidiscursividad del saber criminológico tiene que ver con un registro etnográfico: la existencia del delito, el hecho criminal como un universal de la cultura. Los patrones universales tienen que ver con las semejanzas o similitudes que guardan entre sí las diversas culturas. Éstas, independientemente de su grado de desarrollo social, se componen de instituciones; constituyen una respuesta organizada al mundo de la vida. Ninguna sociedad, según registros antropológicos, explica su existencia al margen de la transgresión y lo prohibido; categorías básicas de la socialidad, pasado y presente de la sociedad humana: la "nebulosa afectual" de la que habla Maffesoli (2004). "No existe placer humano sin una situación irregular, sin la ruptura de una prohibición", escribía (2015: 54). Las comunidades primitivas no están exentas de preceptos o normas regulatorias. Sobre el particular señalaba Foucault: "En cada cultura existen sin duda una serie coherente de líneas divisorias: la prohibición del incesto, la delimitación de la locura, y posiblemente algunas exclusiones religiosas ( ... ) desde el momento en que se señalan los límites, abren el espacio a una transgresión siempre posible" (1990:13). 
El ordenamiento social se institucionaliza con base en normas; éstas dan origen a lo que conocemos como derecho. Éste, consuetudinario o positivo, se define como el conjunto de leyes y disposiciones a que está sometida toda sociedad. Para Hans Kelsen, el jurista y filósofo austriaco, el derecho es una técnica de coexistencia social, diseñada para garantizar la convivencia pacífica de los seres humanos. A su vez, agrega: El "derecho no puede ser separado de la política, pues es esencialmente un instrumento de la política" (Kelsen, 2012: 29). Antes que nada, el derecho es un fenómeno social. El más civil y humano de todos los fenómenos sociales, al decir de Italo Mereu (2003).

Las sociedades poseen, para decirlo con Bourdieu, un "capital cultural". En él se despliegan diversos instrumentos que son utilizados para la apropiación de riqueza simbólica, entre estos se configuran catálogos de normas y reacciones o desobediencia a las mismas. El referente tácito del derecho es el poder. Para Habermas el "derecho presupone una transformación jurídica del poder (...) En esto radica la idea moderna del Estado de derecho" (2000:101). No hay poder sin normas y viceversa. Planteado así, es lógico suponer el interés de diversos autores, disciplinas y religiones, por el delito, un fenómeno social de orden diacrónico y sincrónico.

El orden social ha sido una preocupación universal; la encontramos en la Grecia de Sófocles, Platón o Aristóteles, en el medioevo tomista, pero también en la Europa de Rousseau, Marx, Sorel, o en el mundo globalizado del siglo XXI. Entre la desobediencia de Adán y Eva- el realto de origen-, la sublevación de Espartaco, y los atentados terroristas de Nueva York (2001), Francia (2016), o la expedición punitiva sobre territorios de Irak y Siria, existe un hilo conductor: cierta idea sobre la constitución del orden y el control social basada en el poder, salvando desde luego las respectivas particularidades míticas, históricas o de contexto social. Prevalece la ley del más fuerte. No hablamos de poder en abstracto. El poder es la materialización concreta de la política, la religión o la moral; ocasionalmente estas categorías no son muy evidentes. Todas ellas, no obstante, dibujan la canettiana pasión por el poder. Interrogar lo oculto de la políica o la moral, superando el sentido común como prueba de verdad intelectual indiscutible, esa "apología de la equivocación" de la que hablaba Gramsci, "aprendiendo a pensar" -la gran herencia de la Ilustración-, ha sido tarea de disciplinas como la filosofía del derecho, la ciencia política, la sociología, la filosofía o la antropología.

En su génesis el saber criminológico fincaba su atención en la parte instrumental o técnica del delito, la desviación del orden moral o el disenso, soslayando cuestiones fundamentales como el poder, el orden estructural o los “aparatos ideológicos del Estado", según el vocabulario Althusseriano. Ignorar los referenciales del poder es un absurdo. El poder es la piedra angular de la polifonía social y cultural. En ciertos casos, según demuestran algunos estudios de antropología política, el poder, no es en apariencia, visible, sin embargo está presente; es una constante tanto en los sistemas ágrafos como en los modernos. Los Zuñi, tribu nativa de Nuevo México, por ejemplo, operan mecanismos de distribución del poder, cuya función es desaparecer una pasión tan 
humana como la ambición. La cultura Zuñi invisibiliza el poder, lo enmascara. Para Clastres (2013) el poder es el referente fundamental de la política, una de cuyas manifestaciones más visibles es la guerra.

Lo que por razones expositivas denominamos "saber criminológico", nos remite a la arqueología de la disciplina, un área densa y de difícil sistematización, toda vez que en el aparato discursivo entran en acción formas diversas de interpretación sobre el poder y el control social. Una forma de evitar la excesiva generalización sobre la disciplina es delimitando fronteras de conocimiento. En este sentido, Pavarini, profesor de la universidad de Bologna, ubica como punto de inflexión del saber criminológico -la emergencia de la cárcel como institución: al disponer de un objeto de referencia: el delincuente, ubicado en un espacio concreto, se habilita un lenguaje profesionalizado: un oficio. La división del trabajo abre la posibilidad de inaugurar una profesión concreta: la criminología. Hipotéticamente neutral. Positivista.

Para el teórico italiano, la criminología aparece en el concierto humano, con la emergencia del sistema capitalista, erigido sobre la base de la iniciativa individual y la propiedad privada de los medios de producción. En la misma dirección Foucault (2009) sostiene que disciplinas como la sociología, el psicoanálisis, en coincidencia con la criminología, surgieron en estrecho vínculo con formas específicas de control político y social, en los albores del sistema capitalista. Cronológicamente cubre un periodo ubicado entre el siglo XVI y el XVIII. A mediados de este último se finiquita un capítulo definitivo: la revolución industrial; cenit de la acumulación originaria de capital; paisaje definitivo analizado por Marx en su obra canónica: El capital.

La criminología como ciencia, es decir como campo autónomo, y provista del método científico que descubre en las ciencias naturales, emerge en sentido estricto, con la reducción del criminal a la condición de encarcelado. No antes. El secuestro institucional podría plantearse como paradigma o matriz disciplinar. Situación homóloga la podemos encontrar en el discurso médico sobre la enfermedad. La reflexión sobre las enfermedades del cuerpo o de la mente, adquiere un status científico sólo después de que el sujeto es hospitalizado, siendo susceptible de ser evaluado clínicamente y sometido a procesos de experimentación, de acuerdo a los cánones de la medicina, entendida como ciencia factual (Pavarini, 2003). El interés por la patología social, similar a la preocupación predisciplinaria sobre la salud del enfermo, constituye un antecedente importante en el proceso de constitución de la criminología, pero carece del estatus de una heurística científica, aquella que se desarrolla posteriormente, tomando como piedra angular esa suerte de laboratorio que es la institución carcelaria. La cárcel ofrece al criminólogo, al psiquiatra, al trabajador social, un factum u "objeto de estudio": el delincuente. Las rejas permiten el estudio empírico del comportamiento. La privación de la libertad como sanción penal, es una invención moderna; se adscribe a la reforma penal y procesal del siglo XIX suscrita en el escenario de las libertades burguesas, en sustitución de mecanismos punitivos bárbaros y absolutos.

La cárcel como lugar para purgar una pena tiene orígenes inciertos. Bonne sostiene que la pena de 
prisión surgió en los Estatutos medievales de las ciudades italianas. Von Hippel afirma que el nacimiento de la prisión como pena se ubica en Holanda, hacia 1600. Toma como referencia la prisión de Ámsterdam. Para Eberhard Schmidt la pena privativa se origina en Inglaterra. Finalmente, Norval Morris afirma que la cárcel es de origen norteamericano (García, 1982). Los "cuáqueros de Pensilvania, tienen el mérito de haber inventado o reinventado la prisión”, escribe Morris (1998: 21). En 1790, William Penn, fundador de la colonia, impulsó la construcción de las primeras prisiones con celdas, una de ellas en Walnut Street. Se le conoce como "sistema filadélfico o celular". Seis años más tarde se construyó, la de Newgate, Nueva York.

El modelo filadélfico supone como medidas correctivas, el aislamiento extremo del reo en un silencioso "sepulcro provisional", sin más recursos que dialogar con los fantasmas de su propia conciencia; se le obliga a leer la Biblia y textos religiosos. Los reos tenían prohibido hablar. Llevaban la cabeza cubierta con una capucha. El régimen conducía a un estado de embrutecimiento, ociosidad y perturbación mental. Este sistema se adoptó en Europa entre 1835 y 1851. Para Enrique Ferri, el afamado jefe de la escuela positiva de ciencia criminal, el sistema celular, además de absurdo y brutal, era una absoluta "aberración”.

Décadas después, en 1820, hizo su aparición el modelo Auburn, en la cárcel del mismo nombre. El modelo Auburn decreta la reclusión en celdas individuales, permitiendo algunas actividades en común, como el consumo de alimentos y el trabajo, pero en silencio absoluto. A diferencia del sistema filadélfico, en las cárceles de Auburn y Sing Sing se introdujo el trabajo en talleres o en canteras. La actividad laboral generó inquietud y malestar entre los obreros libres, pues resentían en el trabajo de los prisioneros una competencia desleal. Para Foucault este sistema tiene como propósito reproducir tras el microcosmos de los barrotes una sociedad perfecta, con la disciplina del taller y el silencio que evita el contagio moral (1997). La cárcel no surge al azar. El secuestro institucional aparece en la historia de los hombres en un momento concreto: en el momento en que la libertad adquiere un valor económico (Melossi y Pavarini, 1981).

En Europa, tal como lo sugiere Morris, criminólogo de la universidad de Chicago, existen evidencias de diversas formas de reclusión: buques de convictos, hospicios, reformatorios o casas de labor; ninguna implica, sin embargo, una "condena de prisión". Con el establecimiento de la cárcel, como institución legalmente reconocida, emerge la criminología. Desaparece el espectáculo circense de los suplicios. La cárcel manifiesta cierta "sobriedad punitiva” Foucault (1997), y sobre todo, la humanización en asuntos penales. A su vez, este instrumento de represión, la cárcel, representa en términos fácticos, el poder por excelencia del Estado democrático sobre los ciudadanos (Morris, 1998), una tecnología disciplinaria cuya herencia se prolonga hasta nuestros días. El objetivo nunca alcanzado de la prisión es el "reintegrar" reformado al infractor. Independientemente de las diversas opiniones sobre los orígenes de la prisión, que según parece fue una idea importada de Europa, se reconoce en los norteamericanos el perfeccionamiento de los sistemas de reclusión: los modelos filadélfico y auburniano (García, 
1982); también por los logros alcanzados en el Reformatorio de Elmira, Nueva York, dirigido desde 1876 por Zebulon Brockway, la obra más espectacular del reformismo positivista, centrada en dos objetivos específicos: la corrección y la rehabilitación de los jóvenes delincuentes.

\section{EL PARADIGMA DE LA DEFENSA SOCIAL}

El análisis sobre el periplo de constitución de la criminología como disciplina cubre tres periodos importantes: 1. La escuela liberal clásica, 2. La escuela positiva, y 3. La escuela de Chicago. Las dos primeras tienen en común un pensamiento básico, asociado en lo fundamental, a la ideología de la defensa social. Tienen como punto de partida, un "modelo de ciencia penal integrada (...) la ciencia jurídica y la concepción general del hombre y de la sociedad se hallan estrechamente ligadas" (Baratta, 2004: 35). La tercer escuela está vinculada con el desarrollo de la "sociología de la desviación" en los Estados Unidos.

En los siglos que anteceden al surgimiento de la criminología como disciplina, el delincuente era asumido literalmente como un transgresor del contrato social o catálogo normativo del pacto primigenio. La acción del sujeto vulnera las bases del Estado. En este sentido el interés, en un primer momento, no recae en el delincuente sino en el delito. No es el delincuente (actor) sino el delito, el referente básico de la discusión. Tal como lo plantea Baratta, el delito se concebía como un "concepto jurídico". El delincuente, a diferencia del pensamiento positivista posterior, no poseía características específicas, que lo diferenciaran de los demás miembros de la comunidad o cuerpo social. Es un individuo normal. El sujeto en cuestión, precipita la acción delictiva sobre la base del libre arbitrio, no como consecuencia de una patología (Baratta, 2004). El delito es un acto volitivo. Bajo esta óptica, la sanción penal no aspira a reformar al sujeto trasgresor del derecho. El objetivo de la sanción es único: la defensa social comunitaria, es decir, se busca proteger a la sociedad del ataque criminal. La mejor defensa es el ataque, la muerte, o el castigo físico del transgresor, se plantea. Esta concepción da lugar a un modelo de pensamiento o primer paradigma en el campo de la criminología: la defensa social.

Baratta (2004) resume en seis principios los fundamentos de la defensa social: 1. Principio de legitimidad, 2. Principio del bien y del mal, 3. Principio de culpabilidad, 4.Principio del fin o de la culpabilidad, 5. Principio de igualdad, y 6. Principio del interés social y del delito natural

Estos principios articulan la potestad de lo que Foucault llamaba "economía punitiva" del Estado, y tienen como objetivo salvar la obediencia al pacto social, de aquellos que exhiben un desacuerdo radical con los límites contractuales. En autores como Locke, el contrato o pacto social presupone un consenso mínimo de igualdad jurídica. Bajo la óptica de la defensa social no se exculpa al delincuente, sino que se valida o legitiman todas las acciones del Estado, encaminadas a evitar el caos del comportamiento humano (Lemnek, 2002). En este orden, la razón objetiva del sistema penal clásico y positivo, no es otra que el control de las conductas 
transgresoras. A pesar de la distancia temporal, países como Estados Unidos son, hoy en día, adeptos y cultores de este paradigma. La política antiterrorista que se diseñó tras el ataque a las torres gemelas, el 11 de septiembre de 2001, se fundamenta en el modelo de defensa social. La denominada "incapacitación selectiva" es una forma de racionalidad punitiva, a través de la cual y con técnicas actuariales, se aísla, persigue o expulsa a los sujetos que son considerados "grupos de riesgo": negros e inmigrantes. En Francia, por citar un ejemplo, la política migratoria justifica la expulsión de ilegales como una medida precautelatoria o de contención para neutralizar al otro: minorías potencialmente peligrosas de brindar cobertura a las "células durmientes" del terrorismo que impulsa el Estado Islamico (ISIS).

\section{LA CONSTRUCCIÓN SOCIAL DEL MIEDO}

Massimo Pavarini (2003) acusa de reduccionistas a los autores de los manuales modernos sobre criminología, por dos motivos: 1. Ignorar el pensamiento político-filosófico liberal antecedente, centrando el análisis de manera exclusiva en autores asociados al pensamiento reformador e iluminista del siglo XVIII: Beccaria (Italia), Bentham (Inglaterra) y Hommel (Alemania), es decir, los más comprometidos con el análisis de la legislación penal, y 2. Fincar la atención en aspectos político-jurídicos vinculados con la codificación, el proceso penal y las garantías del imputado, soslayando el escrutinio de los mecanismos socioculturales y políticos de preservación y control del orden social que emerge de las ruinas del antiguo régimen. Para el criminólogo italiano, las ideas modernas sobre el crimen tienen su origen en el pensamiento clásico de Thomas Hobbes (1588-1679). En Leviatán (1651), el filósofo de Malmesbury señala los rasgos definitorios que fundamentan al Estado moderno: se erige teniendo como punto de partida, el miedo. El nuevo orden político surge con fundamentos, no en la teología o en la metafísica medieval que sucumbe, sino sobre la base de un pensamiento racional, cuyo actor es un ántropos de carne y hueso. Al igual que Maquiavelo, Hobbes fija su mirada en una topografía de hombres reales, habitados por sueños y una sed de competencia y conquista: un cuerpo pasional, un ego territorial marcado por el fuego de los deseos.

El florentino y el de Malmesbury, son los artífices de una revolución conceptual: la política deja de ser un arte (práctica), tal como fue concebida por Aristóteles, y se transforma en una técnica. La centenaria idea platónica de lo "justo", la acción prudente, deja de ser necesaria. No lo es en el sentido de que los hombres al interiorizar un grado importante de conocimiento sobre el orden correcto del Estado y de la sociedad, no requieren de la acción prudente (práctica) para mediar sus relaciones, sino de la construcción racional de reglas, procedimientos e instituciones. Para Hobbes la conducta humana reclamaba ser tratada como material científico, a imagen y semejanza de los objetos de la naturaleza auscultados por Galileo Galilei, el físico y astrónomo italiano (1564-1642), siendo, además, susceptible de ser modificada. Según anotan los críticos, el viejo filósofo traslada al 
campo de la política, los recursos analíticos de la revolución galileana; con el tiempo coadyuva rá en la cimentación de la ciencia política y la antropología política (Luque, 1996). Para Hobbes: Todo lo necesario para la salvación se contiene en dos virtudes: fe en Cristo y la obediencia a las leyes" (1990: 485), es decir, al soberano. El Estado, en la concepción hobbesiana, aparece como representación de Dios en la tierra. Pecar, entonces, equivale a desobedecer las leyes, separarse del camino de la sociabilidad. Ahora bien, señala: "Pecar no es solamente una transgresión a la ley, sino, también, un desprecio al legislador, porque tal desprecio constituye, de una vez, un resquebrajamiento de todas sus leyes" (Hobbes, 1990: 238).

Hobbes hace uso de las Sagradas Escrituras con fines didácticos. La Biblia sirve de recurso para fundamentar algunas opiniones. Para Hobbes los deberes religiosos deben subordinarse y guardar obediencia al poder secular del soberano: las leyes civiles se imponen sobre las religiosas; el Estado laico elimina la superstición como norma de acción política. Tesis como estas obligaron al filósofo a huir de los presbiterianos en Inglaterra, y luego de los clericales en Francia, como salvando la cabeza de la temible hacha de los celtas.

La antítesis del pacto social es él caos del "Estado de naturaleza". En él no hay autoridad que haga cumplir la ley; prevalece el imperio del más fuerte. La violencia anárquica antecede a la racionalidad de la ley. No hay contrato. Tampoco leyes que reglamenten el quehacer público y privado. El Estado de naturaleza, no plantea en modo alguno, la hipotética presencia de un instinto asesino en el código genético, tal como lo suponía Robert Ardrey en El imperativo territorial, polémico libro publicado en 1966. Para Macpherson (2005) el Estado de naturaleza, planteado por Hobbes, corresponde a una hipótesis de carácter lógico, no histórica, basada en una prospección genérica de las pasiones humanas. Los kung San cazadores- recolectores del desierto del Kalahari, estudiados por el antropólogo Richard Lee, no reconocen ninguna autoridad jerárquica, y sin embargo son capaces de mantener el orden, evitando el caos (Jacorzynski, 2002). La guerra intergrupal era desconocida para los Kung San. Obligados por las autoridades del apartheid sudafricano fueron empujados a hacer la guerra y perseguir a los vecinos como si fueran piezas de caza. La violencia positiva, organizada, tal como lo plantea Hobbes, se hace visible solamente a través del contrato.

El Leviatán domestica, en el sentido jurídico, las pasiones, y las transforma en prudencia: El individuo hobbesiano, encarnación del Homo homini lupus (el hombre es un lobo para el hombre), el lobo carnicero, tras el proceso de doma, se transforma en un manso cordero; padece en carne propia la desestructuración de la libido dominandi, expresión acunada por Agustín, el obispo de Hipona. Se inhabilita la transgresión. Ésta es una forma temprana de control social. La conducta criminal se fractura mediante el uso de la violencia positiva ejercida por el soberano, depositario de la autoridad conferida por el pueblo.

El derecho a castigar recae sobre el soberano; su voluntad se traduce en la ley. El principio de legalidad en materia penal deviene del contrato: se legisla para el presente. No hay retroactividad. Este es un principio básico 
que fundamenta la reforma penal y procesal del nuevo orden social. Domesticar los deseos es parte del contrato social. El contrato que origina el orden político se estructura sobre la base del miedo, articulando a su vez un esquema jurídico y punitivo. Sobre esa superficie las ideas criminológicas evolucionan hacia una totalidad penal triádica: ciencia, hombre y sociedad. Los filósofos políticos discurren sobre el arte y formas del buen vivir. La base de este pensamiento es el egoísmo y el contrato. George Sabine encuentra en las ideas de Hobbes, una cercanía con la filosofia social de los epicúreos. Para Epicuro, representante de una de las grandes escuelas atenienses del año 306, el hombre no tiene otra necesidad como no sea la de la búsqueda constante de la felicidad individual. Para el ateniense la felicidad consiste en evitar el dolor (Sabine, 1984).

La preocupación básica de Hobbes es la seguridad, la felicidad de los seres humanos. Escribe: "Las pasiones que inclinan a los hombres a la paz son el temor a la muerte, el deseo de las cosas que son necesarias para una vida confortable, y la esperanza de obtenerlas por medio del trabajo" (Hobbes, 1990: 105). Solo el contrato, la dejación de la soberanía individual en manos de un soberano, puede eliminar la incertidumbre: suprime el riesgo de hombres que aceptan la voluntad de los dioses; el obsceno espectáculo de Jehovah, celebrando el olor de la carne quemada. Así lo expresaba bellamente Bataille, el censurado teórico del influyente Colegio de Sociología (2015). El miedo, alarma fatal que transfigura el rostro de los hombres es, que duda cabe, el demiurgo del Estado.

John Locke, a diferencia de Hobbes, no apela al Leviatán, el poderoso dios mortal, obra perfecta de la razón humana, usufructuario de la soberanía, sino al imperio de la razón, la ley universal que gobierna el destino de los hombres. En el Ensayo sobre el gobierno civil (1660) Locke advierte mínimos de racionalidad que aún en el "Estado de naturaleza", permiten la convivencia social de la comunidad. No piensa el Estado de naturaleza como una era de todos contra todos, sino como un momento de "paz, buena voluntad, asistencia mutua y conservación". Admite como carencia, la falta de un derecho escrito y penas fijas que den operacionalidad a la justicia, pero ello no implica un estado de guerra permanente, como suponía Hobbes. En su opinión, el derecho natural confiere a los hombres, derechos y deberes, a partir de los cuales ejerce una convivencia en paz. Transgredir el catálogo de derechos naturales, implica sanción o castigo. El criminal transgrede los límites de la razón, aun así, no es un sujeto expuesto al rigor de un poder absoluto y arbitrario. Se le castiga con base en la razón y la conciencia. Locke se pronuncia por un sistema de leyes. Toma distancia frente a Hobbes que apuesta por el ejercicio de un poder absoluto, "totalitario": la democracia basada en una asamblea soberana de súbditos le parece imposible. En tiempos de perturbación social, el hombre requiere de custodes libertatis: dictadores o protectores de su autoridad (Hobbes, 1990).

Pensar una sociedad sin reglas, normas o preceptos, bajo un consenso absoluto y sin presencia del conflicto, es insostenible. Sólo es posible en el campo de la utopía, en cuyo caso, el verdadero problema sería una aburrida ausencia de problemas. Para la antropología, toda sociedad independientemente de su grado de 
desarrollo social, mantiene formas mínimas de regulación que, en ocasiones, no siempre, se expresan en correspondencia con preceptos morales provenientes de imperativos religiosos. Entre los Andamán, isleños seminómadas, cazadores-recolectores, estudiados por Radcliffe-Brown, el acto de llorar no obedece a sentimiento alguno, sino a un ritual prescrito por la costumbre, como mecanismo social de afirmación solidaria o grupal (Morris, 1995). Se llora por obligación; el llanto se inscribe en los marcos de una concepción del mundo, de la vida y de mecanismos de regulación.

La existencia de reglas o normas constituye un universal de la cultura. Los tabúes son prohibiciones; se enmarcan en el mundo de lo sagrado. Para Durkheim y Eliade lo sagrado se expresa a través de creencias, símbolos y rituales. La presencia de lo sagrado y lo profano es una constante en todas las culturas. Lo sagrado opera como un mecanismo, a través del cual la sociedad y la cultura actúan sobre la conciencia individual. Para Weber los tabúes constituyen un engranaje religioso que fundamenta intereses de orden económico o social; Malinowski diría que el tabú tiene por objeto normar ciertas prácticas en el seno de la comunidad aborigen. Freud sostenía, apoyado en la interpretación de Edipo rey, y en una de sus hipótesis más socorridas, que la construcción de la sociedad humana había sido posible gracias a dos cosas: un homicidio y una prohibición. El asesinato del padre, el parricidio, prefigura el tabú del incesto, el complejo de Edipo, aparentemente un "universal de la cultura". Malinowski aporta información etnográfica que contradice la hipótesis freudiana. Los trobriandeses de Melanesia, a diferencia de la norma parental de patrilinealidad que rige a la familia nuclear en occidente, pertenecen a una sociedad matrilineal: El papel del padre es ocupado por el hermano de la madre. El niño al rechazar el status del padre, plantea el declinamiento del rol de este, siendo sustituido por el tío. El niño no rivaliza ni hace de su progenitor un contrincante. Bajo la premisa freudiana, compartida por psicoanalistas como Ernest Jones y Jacques Lacan, la interdicción del incesto sería el acto fundacional de la cultura. Los tabúes totémicos inauguran la moral humana, toda vez que restringen y prohíben. La culpa, el horror, la seducción por lo prohibido, despliegan, articulan un imaginario colectivo: los trazos culturales bajo los cuales se gesta la reproducción comunitaria (Payá, 2006).

En sentido general, la etnografía de la temática referida al mundo de las reglas sociales y económicas y, en consecuencia, de la configuración del poder, corresponde al campo de la antropología política, una subdisciplina de la antropología social, surgida en torno al libro de Fortes y Pritchard. Los ejes que apuntalan este campo de estudio son tres: el pacto, el orden político y la guerra. El trasfondo de esta trilogía es, desde luego, el poder. Este configura la clave de la política, el punto de partida del control social, siendo a su vez, la base referencial primigenia de la defensa socia 


\section{LOS DERECHOS DEL HOMBRE, REFERENTE CONTRACTUALISTA DEL APARATO NORMATIVO}

La escuela liberal clásica de criminología tiene como premisa fundamental el respeto irrestricto a los derechos del hombre. Se basa en el pensamiento contractualista y utilitario de Hobbes, Montesquieu y Rousseau. Constituye el preámbulo de la criminología positiva. Cronológicamente se ubica entre el siglo XVIII y primera mitad del siglo XIX. Teóricamente incluye un acervo de ideas sobre tres cuestiones: el crimen, el derecho penal y las penas (Taylor et al., 1997)

Tradicionalmente se ubica a Cesare Beccaria, Jeremy Bentham y Anselm von Feuerbach, como precursores de las teorías sobre el crimen. Los manuales escolares aluden a los autores mencionados como padres de la criminología clásica. Pavarini sostiene que es un error. En su opinión cualquier reflexión contemporánea sobre el crimen debe tener como punto de partida a Hobbes y la producción teórica político-filosófica del siglo XVII Y XVIII. Al respecto señala:

Sólo a través del esfuerzo por leer la cuestión criminal dentro de la más amplia reflexión política del periodo, permite evitar la interpretación aún hoy dominante que ve o quiere ver del pensamiento político-jurídico de la época sólo el aspecto, igualmente presente, de la afirmación de la libertad civil en relación con las arbitrariedades del poder, de la defensa del ciudadano contra el príncipe (Pavarini, 2003: 28).

Es decir, aquello que se relaciona con el proceso de crítica hacia un sistema penal obsoleto, que privilegiaba la acción de la justicia sobre el cuerpo, sin advertir que toda legislación implica, de uno u otro modo, la represión del Estado. A finales de la Edad Media la táctica punitiva por excelencia en occidente, era la marca infamante: herir, amputar, "apoderarse del cuerpo y grabar en él las marcas del poder" (Foucault, 1990: 47). Este procedimiento, la marca, se derogó en 1832, en Francia, y en Inglaterra, dos años después.

La escuela clásica cuestiona los procedimientos penales que le anteceden y que retratan la acción infame del poder, los presupuestos de una liturgia de la obediencia. Asimismso, realzan la importancia de una impartición de justicia basada en leyes. El advenimiento de la codificación plantea una ruptura con la acción punitiva del soberano, centrada no en la acción del juez, sino en el castigo directo, corporal, típico del régimen inquisitorial pontificio. El tormento y el uso de la confesión del imputado como prueba reina se mantuvo en algunos países hasta mediados del siglo XVIII. El salto cuántico, del castigo centrado en el cuerpo a la idea del delito y la pena, es un proceso entendible dentro de un contexto histórico concreto: la emergencia del sistema capitalista, y la reconfiguración de las relaciones sociales de producción. La horca es sustituida por el internamiento. Resulta más rentable. Responde a las necesidades de sojuzgamiento de las masas de desposeídos que toman por asalto la ciudad. Las instituciones de control social que emergen del nuevo contrato social, y con ellas, los códigos penales, responden a los intereses del nuevo orden económico social, y de la nueva clase: la burguesía, beneficiaria del 
torbellino social de la revolución francesa.

Los códigos penales -compendio ordenado y sistemático de legislación aplicable en materia penal-son propios del siglo XVIII y XIX: Rusia, 1769; Prusia, 1780; Pensilvania y Toscana, 1786; Austria, 1788; Francia, 1791, 1808 y 1810 (Foucault, 1997). La fase codificadora supone una nueva era en lo concerniente a la justicia penal. Supera la economía del castigo basado en el tormento y el suplicio: el ataque al cuerpo de los condenados. Los códigos plantean un antes y un después respecto de la idea de humanización de la justicia que, en Beccaria, tiene a uno de sus mejores exponentes.

Cesare Beccaria, postula dos elementos importantes: la idea del contrato social y la división de poderes. Estos temas tienen como antecedente El contrato social, de Rousseau (1712-1778) y El Espíritu de las leyes, de Montesquieu (1689-1755); obras que fundamentan una concepción liberal y utilitaria, tanto del Estado como del derecho, y con Beccaria: a una teoría jurídica del delito y de la pena, basada en el concepto de utilidad común. Este último aspecto hace de la teoría del contrato social, una teoría utilitarista. La justicia humana, tiene como aspiración el bienestar de la colectividad: toda pena o acto de autoridad de hombre a hombre, que no se derive de la absoluta necesidad de defender el depósito de la salud pública, es tiránica, escribe el marqués, citando al barón de Montesquieu. El derecho a castigar proviene de la cesión de la soberanía individual al soberano, prevista en el contrato social: obliga al ejercicio de la justicia, no del abuso, que se considera una tradición autoritaria que debe ser eliminada en beneficio de los súbditos de la república o del Estado. Escribe Beccaria:

La necesidad obligó a los hombres a ceder parte de su libertad propia ( ... y es cierto que cada uno no quiere poner en el depósito público sino la porción más pequeña que sea posible, aquella sólo que baste a mover los hombres para que le defiendan. El agregado de todas estas pequeñas porciones de libertad posibles forma el derecho de castigar; todo lo demás es abuso y no justicia: es hecho, no derecho (2000: 217-218).

Abuso es la tortura, el suplicio, la pena de muerte, y la participación del soberano en la decisión de la sanción. Beccaria se opone a estos procedimientos. En su lugar debe proceder la potestad punitiva del Estado, conservando en rigor los derechos del imputado, el principio de igualdad ante la ley, y privilegiando la acción del juez como intérprete de las leyes, tal como lo señala el pacto primigenio. El contrato social y el catálogo normativo que de él emana tienen como propósito utilitario salvaguardar la convivencia social, el depósito público que resguarda los intereses del individuo, en el marco del Estado civil. Para Beccaria (2000) tanto el delito como la pena, deben ser considerados por el juez, teniendo en cuenta los daños ocasionados, y los mecanismos idóneos de defensa social. Advierte cinco premisas: 1 . No procede el castigo sin la existencia de una ley explícita, y sin una conducta igualmente explícita que la transgreda. 2. El objetivo de la pena es disuadir al individuo de comportamientos que vulneren la ley. 3. Las penas deben ser proporcionales al delito cometido. 4. Solo las leyes pueden decretar las penas; esta autoridad, reside exclusivamente en el legislador, y 5. Las leyes deben procurar un tiempo razonable para la defensa y acumulación de pruebas del inculpado. Beccaria menciona pero no se detiene 
en el análisis de la cárcel; se inclina por este recurso solo como sustituto de un castigo excepcional: la pena de muerte.

El concepto de defensa social constituye uno de los primeros paradigmas del saber criminológico, siendo también una ideología. Baratta ubica la génesis de la defensa social en un proceso simultáneo al de la revolución burguesa. Al mismo tiempo la ciencia y la codificación se imponen como elemento esencial del sistema jurídico burgués. En ese tenor, la teoría penal clásica, posee en la defensa social, y en la teoría del contrato, su argumento central (Baratta, 2004).

\section{LA CRIMINOLOGÍA COMO DISCIPLINA POSITIVA}

Gian Domenico Romagnosi (1761-1835), filósofo y jurista italiano, posee una cercanía relativa con Beccaria; su perspectiva filosófica es distinta, está impregnada de esencialismo. Coincide con Beccaria en el ideario de la defensa social, la salvaguarda del bienestar y la búsqueda de la felicidad como bien común. La penalización al actuar como contra estímulo, aseguraría la vigencia de los objetivos sociales antes señalados. La pena se materializa en forma dual: uno, como prevención y dos, como contra estímulo criminoso. Romagnosi, autor de Génesis del derecho penal (1791), define al delito como todo aquello que agrede al bienestar social, o centro moral normativo. Si la conducta delictiva no es reprimida, la impunidad vulneraría las bases que sostienen a la sociedad. Eliminar la impunidad, la amenaza de la conducta delictiva, será una de las tareas del derecho. La sociedad contractual posee el derecho a castigar las conductas que se desvían. Romagnosi no ignora la culpabilidad de la sociedad en la construcción del hecho delictivo. Apoyado en la cartografía moral de Adolfo Quetelet, afirma que el delincuente es solamente un ejecutor, de los delitos que la misma sociedad construye o facilita. Los actos delictivos son impulsos cuya causa se origina en carencias sociales. Opinión similar se encuentra en Rousseau. En su apología del buen salvaje, defendida ante la Academia de Dijón (1750), el ginebrino sostuvo: "El hombre nace bueno y la sociedad lo corrompe". La tesis de Rousseau contradice el planteamiento de Hobbes. Este veía en el hombre a un sujeto pasional, instintivo, malo por naturaleza, que requería ser tutelado por un estado fuerte, superpoderoso: el leviatán.

Romagnosi tempranamente advierte la necesidad de la intervención estatal con el objeto de prevenir el florecimiento de conductas criminógenas o peligrosas. En su opinión, el Estado está en la obligación de aplicar políticas públicas que coadyuven en la transformación de las condiciones objetivas de la vida social: económicas, culturales, de educación y de justicia. La acción gubernamental sobre los entornos socioculturales, debía enmarcarse en una política cercana a lo que Enrico Ferri, años más tarde llamaría: "sustitutivos penales", esto es, medios de prevención social. La perspectiva de Ferri es importante ya que propugna por enmarcar el derecho penal en el ámbito de la sociología criminal, dejando atrás la socorrida tesis del liberalismo clásico basada en la 
idea del delito como ejercicio del libre arbitrio. Esta idea es para Ferri, jurista y parlamentario, una "ficción"; el delito tiene su génesis en la injusticia social. Romagnosi difiere de Beccaria en el análisis sobre el contrato social. Duda del pacto. La asamblea soberana le parece insostenible. Piensa que el hombre es un ser racional y, en consecuencia, de "naturaleza social". En ese sentido es apenas obvio suponer, que en el proceso de evolución social, aísle e identifique las leyes que rigen la sociedad: las leyes sociales son leyes de la naturaleza. Romagnosi supone que la conservación de la especie, es la piedra anular del derecho natural (cfr. Baratta, 2004).

Francesco Carrara (1805-1888), nacido en Lucca, es considerado el artífice del diseño de una construcción lógica y coherente del sistema penal, posibilitando el nacimiento y consolidación del moderno derecho penal italiano. Una obra de obligada referencia es su libro Programa del curso de derecho criminal, publicado en 1859. En sus páginas Carrara efectúa una portentosa reconstrucción de la filosofía del derecho penal italiano, concluyendo en una síntesis lógica del mismo. Para Carrara el delito es un "ente jurídico", no un fenómeno natural; supone la violación de un derecho. La pena se ejerce como tutela jurídica, sin más finalidad que el restablecimiento del orden, la defensa social: la eliminación del estado de incertidumbre que precede a la impunidad del delito. Para Carrara, miembro de la comisión redactora del Código penal italiano, la finalidad de la pena no era ni la retribución ni la enmienda (Baratta, 2004). A tono con las premisas de Beccaria, Carrara, depositario de una suerte de liberalismo católico, apuesta por el respeto irrestricto de los derechos individuales.

Las obras de Beccaria, Romagonsi y Carrara, pero igualmente las de Filangiere y Carmignani, anteceden de forma importante al uso del positivismo como recurso analítico; éste inaugura la fase moderna de la criminología como disciplina científica. A ella se adscriben Tarde y Listz. Gabriel Tarde (1843-1904), originario de Francia, y cultor de la sociología, la criminología y la psicología social. Se desempeñó como magistrado. Esta actividad le permitió desarrollar algunas ideas sobre las fases psicológicas del crimen. Apoyado en algunas hipótesis sobre lo que llamó "mente grupal" y "psicología económica", acuño la definición del delito como una conducta basada en el fenómeno de la imitación y la innovación. La obra de Tarde adquiere renovada vigencia en Estados Unidos, gracias a la recuperación que de sus tesis hicieron los sociólogos de la escuela de Chicago, para explicar el submundo de las culturas desviadas. Franz von Listz (1851-1919), nacido en Viena, y partidario del positivismo jurídico o formalista, se interesa en la acción en términos físicos y en el análisis de las causas del delito. Plantea que el delito es una conducta o acto humano culpable, violatorio de las reglas jurídicas establecidas por el Estado, y en consecuencia, castigado por una pena. El crimen es un hecho, la pena una legítima consecuencia.

A los autores anteriormente citados se agrega el lombardo Enrico Ferri (1856-1929), alumno de Lombroso, al igual que Garófalo, jurista destacado, uno de los mayores oradores forenses de su tiempo. Cultivó la sociología y la militancia política en el Partido Socialista. Entre sus preocupaciones académicas destaca su interés por indagar las causas sociales y económicas que propician el delito, además de proponer sustitutivo penales. Ferri 
se opone al biologismo de Lombroso. Este consideraba que el "delincuente nace, no se hace”. En su opinión no era la ley penal, la encargada de reducir la delincuencia, sino la justicia social. Abogó por la redacción de un "código penal científico". Sus tesis no fueron del agrado de Mussolini. Paradójicamente Ferri, en los últimos años de vida defendió al régimen fascista, lo cual demeritó la importancia de su obra. Rafaele Garófalo era nativo de Nápoles (1851-1934), jurista y criminólogo. Se desempeñó como juez y procurador. Autor de una obra básica: La criminología. Estudio sobre el delito y sobre la teoría de la represión (1885); se le atribuye la paternidad del término "criminología". Garófalo compara a la sociedad con un organismo afectado de células cancerosas. La única opción para el organismo es la eliminación de las células infectas; en el caso de la sociedad humana, además de la eliminación -ecuación cáncer-delito- agrega la reeducación del sujeto criminal. Asimismo considera que los criminales son portadores de una anomalía o lesión moral y psíquica, a partir de la cual se generaba el impulso criminógeno. No era partidario de la pena perpetua. Creía que debía ser sustituida por la pena capital.

Cesare Lombroso, es originario de Verona, Piamonte, (1835-1909); su trabajo esta vinculado a Ferri y Garófalo; no solo fueron sus alumnos, sino que también contribuyeron a sentar las bases de la escuela positiva y de la criminología como ciencia, tomando como premisa la utilización del método experimental. Normalmente se ubica el día 15 de abril de 1876, como fecha inaugural de la criminología como ciencia. En este momento, de acuerdo al el pie de imprenta, se publica la edición príncipe de Tratado antropológico experimental del hombre delincuente, del célebre veronés. Los manuales de la disciplina llaman a Lombroso: padre de la antropología criminal.

Según se desprende de la biografía escrita por Gina Lombroso, la segunda de sus hijas, el médico psiquiatra y criminólogo, pensaba que el delito era una conducta atribuida a tendencias innatas o genéticas. Al parecer, llegó a esta conclusión luego de examinar algunos cráneos de infractores de la ley, entre estos el de un célebre delincuente conocido como el "bandolero de Vihella. En El hombre delincuente (1876), Lombroso calificaba el delito como ente natural: "Un fenómeno necesario, como el nacimiento, la muerte, la concepción", determinado por causas biológicas de orden hereditario. En su opinión el "criminal nato", el hombre delincuente, portaba rasgos físicos atávicos. En una edición posterior, la quinta, restringió el uso del atavismo a tres tipos de delincuentes: epiléptico, demente y ocasional, quizá como resultado de sus investigaciones empíricas en el manicomio de Pesaro, en el que se desempeñó como director, o porque reconocía cierta razón en los críticos que señalaban la generalización excesiva y la precariedad de sus métodos. Señalemos una curiosa paradoja: Lombroso dispuso en su testamento la donación de su cráneo a una institución científica. Años después el cráneo fue analizado y las medidas coincidían con los parámetros del delincuente nato, que el mismo había establecido.

Al criminólogo italiano le llamaba la atención la forma del cráneo y las características del rostro. Defendía la idea de que los criminales no habían evolucionado correctamente. Biológicamente correspondían a fases 
primarias del desarrollo humano. Anormales de naturaleza degenerada. De ahí la obligada tendencia a la conducta desviada. En uno de los pasajes más citados de su obra, señala al hombre criminal con las siguientes características:

Un ser atávico que reproduce en su persona los instintos feroces de la humanidad primitiva y los animales inferiores. Mandíbulas enormes, los pómulos altos, los arcos superciliares prominentes, las líneas aisladas de la palma de la mano, el tamaño excesivo de las órbitas, las orejas con forma de asa que se encuentran en criminales, salvajes y monos, la insensibilidad al dolor, la visión extremadamente aguda, tatuajes, indolencia excesiva, afición a las orgías, y la búsqueda irresistible del mal por el mal mismo, el deseo de no sólo de quitar la vida a la víctima, sino también de mutilar el cadáver, rasgar la carne y beber la sangre (cfr. Taylor et al,, 1977: 59)

No obstante el naturalismo descriptivo, los planteamientos de Lombroso, constituyen un referente importante, en el proceso de llenar los vacíos que dejaba el derecho penal clásico italiano: la explicación de las causas que producían el hecho criminal (Baratta, 2004). Posteriormente se ha desarrollado una secuela de teorías, que al igual que las tesis biologicistas, centran en la naturaleza del individuo o en la mente del infractor, las causas de la transgresión o conducta desviada. En esta línea se agrupan diversas teorías de corte psicologista, a partir de las cuales se buscan explicar las denominadas conductas psicopáticas o tipos de personalidad anormal. Normalmente dejan fuera el análisis de aspectos estructurales, como el entorno sociocultural en el que se desenvuelven los sujetos. Esta falencia ha tratado de ser llenada por disciplinas como la psicología social.

El pensamiento de los autores anteriormente citados, al margen de sus diferencias y matices, se ubica en la tradición del positivismo comtiano y el naturalismo decimonónico. La obra de Charles Darwin, Herbert Spencer, y los avances registrados en las ciencias naturales, influyeron notablemente en la construcción de un nuevo paradigma: el etiológico, esto es: el análisis de las causas y factores que generan la conducta criminal. El pensamiento filosófico de autores como Beccaria es sustituido por procedimientos que se apegan al rigor de las ciencias naturales. Asumen la unidad del método científico. Los actos humanos pueden ser estudiados con los mismos instrumentos de análisis del mundo físico. El método inductivo, experimental, es para Ferri, la clave para evaluar los hechos. La teoría y práctica de la criminología positiva señalan la necesidad de construir una ciencia del delito, cuya base sea la cuantificación, la objetividad y la causalidad. Para Ferri, Tarde y Garófalo el delito posee cualidades que lo identifican con las cosas del mundo natural. Siendo la criminología positiva un saber empíricoinductivo, su interés se finca en las causas de la criminalidad. Analiza y estudia a los delincuentes. Su acción instrumental se limita al análisis de los delincuentes detenidos en las instituciones del estado: la cárcel, el manicomio, el reformatorio (Pavarini, 2003). Uno de los objetivos prácticos será descubrir mecanismos para modificar la conducta del trasgresor. La criminología, será entonces, el estudio de las causas, y a su vez, una política de intervención sobre el sujeto criminal. No se ocupa, en modo alguno, de los procedimientos de identificación que se aplican para el esclarecimiento de crímenes. Lograr que los indicios se transformen en pruebas jurídicamente válidas, corresponde al campo de trabajo de otra disciplina: la criminalística. 
La criminología positiva se distingue del pensamiento clásico porque plantea el delito como un ente jurídico; ubica al individuo infractor como parte de una totalidad biológica, psicológica y social. El delincuente no existe como sujeto abstracto del libre albedrío. El derecho que califica el delito como hecho humano no debe separar la acción del individuo de la totalidad natural y social de la que forma parte. Desde esta perspectiva la atención se ubica tanto en el autor de los delitos como en la personalidad del delincuente. La criminología positiva se auto limita al análisis del sujeto encarcelado. La cárcel opera como un laboratorio donde el recluido es objeto de observación; el sujeto enjaulado contribuirá a develar las causas de la criminalidad.

Si para la escuela clásica lo importante era el delito, como acto volitivo, para la escuela positiva lo será el delincuente. El delito como acto de libre voluntad, es indemostrable, acusan los positivistas; advierten que la normatividad penal no puede configurarse con base en la "objetividad del delito". En su opinión, el sistema penal debe advertir la importancia del microcosmos del sujeto: su contexto ontológico, es decir, su experiencia biológica, psicológica y social. A la imputabilidad absoluta del delincuente, los positivistas aventuraban un determinismo biológico, que con ciertos matices influye en algunas teorías criminológicas del siglo XX. Finalmente, parecen concluir los criminólogos herederos de Lombroso: el delito existe porque algo no funciona bien en el individuo. En ese sentido, tal como ha señalado Luigi Ferrajoli, la sustitución del criterio de responsabilidad individual -libre arbitrio- por el de peligrosidad social, y el asumir el delito como síntoma de patología psicosomática, constituye la gran herencia de la escuela positiva o antropológica del derecho penal, que aún en la actualidad sintetiza muchas políticas de control social, orientadas a curar las causas del delito o las conductas que escapan a la norma, con paliativos terapéuticos y pedagógicos.

\section{LA SOCIOLOGÍA CRIMINAL ESTADOUNIDENSE}

La criminología contemporánea es básicamente estadounidense. Se le denomina así a una serie de teorías elaboradas en los años treinta, y que se agrupan bajo el nombre genérico de sociología criminal o sociología de la desviación. El objetivo de estas teorías será "estudiar el comportamiento desviado con significación penal, su génesis y su función dentro de la estructura social dada” (Baratta, 2004: 15). Los años de la primera posguerra, como veremos más adelante, son fundamentales para la sociología, una disciplina que enraíza y fructifica espectacularmente en la cultura norteamericana. La sociología crece en forma rápida, más que en ningún otro lugar, al extremo de que como advierte Gouldner: "Para buena parte del mundo actual, 'sociología' es prácticamente sinónimo de 'sociología norteamericana” (2000:29).

La sociología estadounidense florece al amparo de una política de estímulos y beneficios desarrollada por el Estado Benefactor. En esta dirección, como señala Gouldner, citando a Wright Mills, existe una coincidencia temporal entre la era moderna y la de la sociología; son eras que coinciden. Dos generaciones 
después de la Primera Guerra Mundial, la sociología norteamericana prácticamente desplazó a la sociología europea, en técnicas, métodos y referentes teóricos. Los enfoques sociológicos dan lustre y fundamentos a la criminología estadounidense. Cuatro teorías ilustran a la sociología criminal: 1. Teoría Funcional-estructural. 2. Teoría de la anomia. 3. Teoría de las subculturas, y 4. Teoría del etiquetamiento. Esta última registra un cambio de paradigma en criminología, y se asocia, en lo fundamental, con la emergencia de los transgresores contemporáneos, artífices de los llamados "delitos sin víctima", sobre los cuales se ejerce una política de control social (Larrauri, 1992).

Europa, tal como lo hemos reseñado, es la cuna del saber criminológico. No obstante, en la coyuntura del New Dealinspirada en Keynes y desarrollada por Roosevelt, en los treinta, la criminología del viejo mundo es desplazada por el empuje apabullante de la naciente sociología norteamericana. En términos de construcción disciplinaria, escuelas importantes como la alemana y la italiana, pasan a un segundo plano. La emergencia del totalitarismo nazi-fascista, en las décadas de 1920 y 1930, de un lado, inhibe las investigaciones empíricas, y del otro, limita el campo de trabajo de la criminología reduciéndola al papel de ciencia auxiliar del derecho penal. Situación parecida es la de Inglaterra, donde el análisis criminológico quedó anclado en el arcano del positivismo clínico o médico legal. La criminología europea, casi hasta fines de los sesenta, es principalmente académica. De ella se ocupan los médicos legistas y los psiquiatras. Los modelos explicativos empírico sociales, basados en los aportes de la antropología o la sociología, son excluidos, acentuando una visión hegemonizante, penal y médicopsiquiátrica. Es bastante significativo el hecho de que la enseñanza de la criminología quede bajo la tutela de las facultades de medicina (Pavarini, 2003). Una situación contraria es la que se registra en Estados Unidos. En este país la criminología es parte de la curricula de las facultades de sociología.

La era moderna de la sociología criminal estadounidense, y su respectiva hegemonía en el mundo académico, tiene un antecedente importante en los trabajos de la Escuela de Chicago, epicentro del vertiginoso proceso de institucionalización de la sociología como oficio profesional. Esta escuela posee, entre otros méritos, el haber inaugurado los Social Survey: estudios de problemas sociales concretos o empíricos, cuyos alcances destacan en la tradición de la disciplina criminológica. Los cimientos de la criminología estadounidense descansan en teorías sociológicas. La obra más reveladora e impactante de la criminología norteamericana, se debe a la pluma del sociólogo Edwin Sutherland (1883-1950) -alumno del ex baptista Charles R. Henderson, experto en cárceles y delincuencia juvenil-, autor de dos obras de obligada referencia: Ladrones profesionales y El delito de cuello blanco. En estas obras Sutherland contribuye a superar el determinismo positivista que, en el caso de Europa, había conducido a la patologización del delincuente. La delincuencia era un síntoma; el delincuente un enfermo social. Bajo estos rótulos, la conclusión era clara: tratar la dupla delincuente-delito, a imagen y semejanza del galeno que ataca la enfermedades del cuerpo: la ciencia, sobre la base del llamado positivismo clínico, conduce 
al médico al descubrimiento de los mecanismos internos de la enfermedad; a partir de este reconocimiento el cirujano accede a la aplicación de las respectivas técnicas quirúrgicas.

\section{LA OTREDAD DEL OUTSIDER}

Los criminólogos tanto clásicos como positivistas, hablaban de "delincuentes". Teórica e ideológicamente se identificaban en la causa común de la defensa social, es decir, en una concepción del delito y el control social, que tiene como objetivo salvaguardar el bienestar e intereses de la clase social que emerge con la revolución burguesa de 1789. En Estados Unidos, el vocablo políticamente correcto para calificar al transgresor es outsider. Este vocablo sirve para identificar a todas aquellas conductas que se apartan del catálogo normativo establecido en el contrato social. Los estados, sin excepción, poseen un conjunto unitario y sistematizado de normas jurídicas. A través de ellas se ejerce el control social. Violar las normas, individual o colectivamente, implica asumir una desviación social, esto es: apartarse del centro normativo. Esta situación es, al parecer, una constante en el saber criminológico y, desde luego, acompaña a las sociedades humanas desde sus orígenes, tal como lo demuestran variados registros etnográficos y superficies narrativas. El concepto es polisémico, más aún si lo relacionamos con la categoría del mal y sus representaciones clásicas, en el mito o la tragedia.

El viraje semántico tiene como campo explicativo, causas socio políticas y culturales cualitativamente diversas. La coyuntura estadounidense es diferente a la del viejo continente. En este orden, el tema de la composición social de Estados Unidos, como un país de migrantes es definitivo. Da origen, entre otras cosas, a una suerte de ideología del melting pot o crisol de razas. Mito también del sueño americano de un país en construcción.Estados Unidos registró entre 1815-1860 y 1870-1915, una de las avalanchas migratorias más grandes en la historia moderna: cerca de 25 millones de pobres, "obreros de máquina”, provenientes de Europa, atraídos por la utopía de instalarse como "miserables granjeros, pero amos en su casa, en las tierras libres del Oeste" (Coriat, 2011: 9). En 1900, Estados Unidos es habitado básicamente por inmigrantes: de una población de 76 millones, aproximadamente 26 millones, uno de cada tres habitantes, había nacido fuera. La multiplicidad racial y étnica, constituyen, al lado de las diferencias de clase, un componente inédito en la estratificación social del país. Este aspecto diferencia a Estados Unidos de otros países industrializados (Zermeño, 1988).

El flujo migratorio incesante hacia tierras americanas, es uno de los resultados de la violencia económica y política que precipita la revolución industrial. El desplazamiento poblacional de campesinos expropiados es tan alto, que según reseña Marx en El Capital, la Cámara de los Comunes, al igual que en otros países, establecieron la prohibición de emigrar, salvaguardando así los intereses de la burguesía. La industria requiere de brazos y salarios bajos. Impedir la huída de la fuerza de trabajo hacia la ex colonia, es una política de contención y control social. La restricción del derecho a emigrar, no resuelve el problema del hambre. Las industrias manufactureras retienen a 
sus obreros, pero el problema de fondo, los bajos salarios, se mantienen en el límite perverso de la sobrevivencia. La única opción que deja el capitalismo salvaje está del otro lado del mar, en la estival hierba de los prados, el edén imaginario de Whitman.

La sociología surge y se consolida como disciplina en los años críticos de la migración, paralelo a la emergencia de nuevos equilibrios o ajustes forzosos a los derroteros económicos de la producción en masa, o formas moderna de acumulación de capital, surgidas del fordismo, el capitalismo sólido del que habla Bauman (2002) Señalemos que a mediados de 1924 se pone fin a la inmigración irrestricta. Años después, en 1932, Roosevelt, advertía en una célebre alocución: "Nuestra última frontera ha sido desde hace tiempo traspasada, y ya no hay prácticamente tierras vírgenes ( ... Y Ya no queda una válvula de seguridad en forma de un Lejano Oeste (cfr. Coriat, 2011:94).

Uno de los principales retos de la flamante disciplina, es justamente, trabajar el tema de la integración de los inmigrantes a la comunidad nacional; plantear respuestas y soluciones concretas a los problemas sociales. El éxito de la disciplina se basa en estrategias de intervención: es una sociología aplicada, operativa e instrumental; trabaja sobre procesos de transformación cuyo resultado final no ha de ser otro que el disciplinamiento social de los sujetos que rehuyen u obstaculizan la certeza del bienestar normativo.

El delincuente, herencia del discurso jurídico penal decimonónico, es sustituido por un concepto más dúctil: el sujeto de conducta periférica o marginal. El outsiderr es parte de un proceso sociodinámico. Su personalidad exhibe, no una conducta criminal innata, sino los rasgos del malestar social y cultural, el colapso de la no integración o asimilación. La peligrosidad social de la criminalidad, advierte Pavarini, es "recuperada y exorcizada como momento de necesaria y fisiológica conflictividad, siempre armonizable en términos funcionales al sistema" (2003: 62). Así las cosas, la sociología de los años treinta, es una sociología con la impronta de una "pasión evangélica" que acompaña a los sociólogos en su papel de reformadores sociales. La criminalidad sería, entonces, una forma de desviación social, a partir de la cual pueden explicarse todos los fenómenos de integración que enfrenta la sociedad norteamericana: alcoholismo, mafias, bandas juveniles, prostitución, homosexualidad, consumo de drogas, etcétera. Bajo la óptica reformista y moralizante de los sociólogos estadounidenses, los infractores ejercen una conducta que se aparta de la norma, son outsiders "extraños", dice Howard Becker- no criminales. Era, quizá, una forma de relativizar la conducta “anómica". El término fue acuñado por Durkheim en 1893. Lo usó para explicar la ruptura o disociación patológica entre individualidad y conciencia colectiva, que se produce en el marco de la división social del trabajo. La anomia, es un hecho social. Útil. Necesaria, en el sentido de que la sociedad se ve obligada a reaccionar positiva y defensivamente frente a conductas imprevistas.

El punto de partida de la sociología criminológica que se desarrolla en Estados Unidos, en la era del crack bursátil y la Gran Depresión, es la ruptura con teorías que argumentan el carácter patológico de la criminalidad. Si 
el delito depende de las instituciones sociales, el análisis de este tiene que ser necesariamente sociológico. Ese es el avance y vínculo fundamental entre la sociología, la criminología, la antropología urbana y la psicología social.

\section{EL SUJETO ANÓMALO, ANTÍTESIS DE LA LITURGIA DE LA OBEDIENCIA}

La desviación es una conducta que se rige a contrapelo de la conducta general, supuestamente "normal"; el vocablo usualmente se relaciona con la sociología estadounidense. El concepto ha sido utilizado para explicar comportamientos atípicos en el seno de la sociedad. Entender, digamos, la criminalidad, la desorganización social de los inmigrantes, las reacciones juveniles o contraculturales en un mundo de abundancia. El término tiene antecedentes en la vieja Europa. La desviación, en sentido general, implica el alejamiento de la "enseñanza recta y justa”, la oficial; es el pensamiento no canonizado, la autonomía intelectual, el no estar integrado” (Mereu, 2003: 31). La desviación, planteada como pensamiento autónomo, conduce a la herejía; posee como soporte argumental la visión católica de consenso o represión. La base es cierta liturgia de la obediencia. En este orden de ideas es lícito aceptar que cada sociedad posee un catálogo propio de extraños, transgresores excéntricos y, en consecuencia, una política criminal ad doc.

El siglo XIX es por antonomasia, el punto de obligada referencia en el análisis de las conductas anómicas: el suicidio, el robo, el atraco, la estafa, la prostitución. La desviación tiene también un componente de género asociado a la expansión urbana. Nada retrata mejor los problemas que devienen de la macrocefalia citadina que la figura de la prostituta, personaje de culto de narradores y poetas. La puta encarna el imaginario urbano de la perversión. Asimismo son desviados, los inmigrantes, los consumidores de drogas, los delincuentes juveniles, los homosexuales, las lesbianas y, en general, los pobres: las clases peligrosas, el desempleado, el vagabundo, el pordiosero. El miedo hacia el otro es cultivado por los nacientes medios de comunicación escrita. En sus páginas anticipan una política de pánico moral; apoteosis de alarma frente a los cambios que la modernidad introduce en las urbes, entre estos la incertidumbre, la carencia de certezas: La conciencia del tiempo nuevo, esa "morada de los hombres nuevos", advertida por Novalis, y que se expresa mediante metáforas sociales, expresiones del desgarro de un mundo que no alumbra para todos, y que han pasado a la posteridad gracias a los estetas de la vanguardia, tanto en el campo de las letras como en las artes plásticas. La ciudad es un asilo para desamparados, el espacio de las heridas urbanas y el desconsuelo.

\section{INMIGRANTES, INTOLERANCIA Y EXCLUSIÓN SOCIAL}

Estados Unidos es un país de migrantes. La primera oleada de blancos, anglosajones y protestantes, WASP por su sigla en inglés, llegó cuando América era colonia de Inglaterra. El primer grupo de inmigrantes se estableció en Virginia, en 1607, dedicándose al cultivo de tabaco y al comercio de esclavos. El primer "cargamento" de 
negros llegó a Virginia en 1619. Este mismo año llegó un "lote" de mujeres blancas. Los colonos pagaban a una compañía de Londres "150 libras de la mejor hoja de tabaco" por cada una (Pereyra, 1938:52). Las compraban para esposas. A estos primeros inmigrantes debemos agregar los disidentes religiosos o cuáqueros, que se establecieron en Plymouth. En el siglo XVIII forjaron la nación. Los WASP de primera generación monopolizaron la vida económica y política del país, independiente desde el 4 de julio de 1776 y cuyos ideales están plasmados en la Declaración de Virginia del mismo año.

Los inmigrantes de fines del siglo XIX y principios del XX llegan en momentos en que la conquista del Oeste ha culminado, la tierra ha sido expropiada a los indios y las fuentes de trabajo se concentran en las ciudades. Ya no son bienvenidos. Sin posibilidad de acceder a unos cuantos acres de tierra para iniciarse como pequeños granjeros, el único espacio de sobrevivencia es el trabajo en el área de la construcción o de servicios. La precariedad es una característica que comparten los migrantes y sobre esa "base situacional" se configura la conducta criminal. Culturalmente son identificados con el otro, el extranjero, portadores de una naturaleza extraviada que se manifiesta en un metafórico "mundo paralelo", tal como lo planteaba Georg Simmel. Los sujetos cargan sobre sus hombros el peso de dos "desorganizaciones", una, social, y la otra, individual. Esta característica traza el camino que hipotéticamente conduce a los individuos a actuar al margen de la ley.

El inmigrante pobre de la segunda y tercera generación encarna a fines del siglo XIX y principios del XX la figura de la exclusión social, víctimas pioneras de la estigmatización o de la criminalización de conductas. La pobreza parece ser el caldo de cultivo de lo que algunos medios denominan "clases peligrosas". Y, zquiénes son esas clases peligrosas? Los otros. Aquellos que se ubican fuera de las esferas productivas de la sociedad industrial o que se encuentran al margen de una actividad laboral, lejos de la ética del trabajo y de un principio de racionalidad basado en la idea "el tiempo es oro" (Juliano, 2004). La pobreza no se explica en términos estructurales sino en argumentos inspirados en el darwinismo social.

El inmigrante oscila entre dos procesos: la desorganización y la reorganización. El primer aspecto involucra los puntos de ruptura con la comunidad de origen y todo lo que ello implica. La reorganización, alude a los procesos de "adaptación" urbana. Esta última se puede presentar de forma positiva o negativa. La adaptación es positiva cuando se hace visible a través de un paulatino posicionamiento laboral y cultural, destacando como hecho fundamental el adquirir la nacionalidad, y asimilarse como parte del sueño americano, compartiendo un lenguaje común e interiorizando el consenso normativo. La adaptación es negativa, cuando el proceso de asimilación intercultural se se vive y experimenta como colapso: el inmigrante se asume como extranjero, es el otro, el "tartamudo social", el errante, el nómada. Inhibido frente al lenguaje del nuevo hábitat, el inmigrante se autoexcluye de los lazos de socialidad e insiste en los referentes comunitarios que dejó atrás. Tiende a reinventar la comunidad de origen agrupándose por nacionalidad o etnia. Es normal, entonces, detectar cierta "ruralización de 
la ciudad" basada en "actitudes". La reorganización, en términos individuales, implica un reinventarse la vida de otro modo.

Una de las contribuciones más importantes para el análisis de la desorganización social de los inmigrantes corresponde a la obra de William Thomas y Florian Znaniecki, El campesino polaco en Europa y los Estados Unidos de América, publicada entre 1918 y 1920. Los autores advierten el declive de los valores colectivos ancestrales, los cuales son sustituidos por una valoración inédita del individualismo posesivo, asociado al campo de las prácticas sociales. El periplo migratorio fragmenta los vínculos identitarios, reemplazándolos por reglas urbanas socioliberadoras; a través de éstas el individuo se reconstituye. La socialización de la experiencia urbana permite al individuo la apropiación de un universo simbólico comunicante. Frente al caos de lo desconocido, una estrategia de supervivencia para el inmigrante pasa por la reorganización primaria, o grupal. La quiebra de los valores comunitarios de la "comunidad imaginada", se compensa con la adquisición reafirmante de los valores pragmáticos de la comunidad de llegada. El prestigio de origen comunitario se resignifica en nuevas formas de reconocimiento social: jefe de banda, contrabandista de alcohol, pollero o tratante de blancas.

Para los sociólogos de principios de siglo, el proceso descrito, era el escenario en el que se gestaba la conducta desviada. De ahí su interés, en términos de investigación, en la fase de reorganización individual. Asimismo señalaban, superando las tesis de la antropología criminal, que la reorganización tiene que ver con problemas de orden social y cultural, y no con balumbas de orden mental, derivados de características de orden biológico o racial, tal como lo suponía Lombroso.

El inmigrante actúa en un medio social específico que, en primera instancia, le provee información necesaria, le advierte sobre la situación a enfrentar. Cada situación le obliga a un proceso de interpretación. La única referencia es su "capital cultural" interno. En este sentido el individuo confronta su propio pensamiento con el pensamiento colectivo de la sociedad. Citemos un ejemplo: "robar es malo", piensa el sujeto; su reflexión parte de un análisis situacional de orden interno. Ahora bien, si careces de empleo, es normal que tomes a la fuerza lo que deseas o te hace falta. La justificación moral proviene del entorno social externo, una de cuyas bases, incluso, tiene sustento en la religión. El caso más paradigmático quizá sea el de los sicilianos. Las hermandades y mafias originarias del sur de Italia, operan como entidades comerciales que brindan protección privada extralegal y gozan de la bendición de la religión católica (Gambetta, 2007). La virgen de Santa Rosalía, patrona de Palermo, es la protectora de las gangs americanizados; Jesús Malverde lo es de las mafias mexicanas que operan en San Francisco y Chicago. El pacto se sella con gotas de sangre derramadas sobre las imágenes, objeto de su devoción. Los inmigrantes reactualizan rituales liminales, propios de las culturas orales; imaginariamente se reinstalan en sus comunidades de origen: sobreviven como fantasmas en los múltiples perímetros de la memoria, lubricando heroicamente el "ejército de reserva" del sueño americano. 
El inmigrante encarna la figura moderna en la cartografía del outsider, el que rompe las reglas como un mecanismo de supervivencia, y que se refugia en formas nuevas de asociación, en las que aprende por "asociación diferencial", término acuñado por Sutherland para describir el proceso de aprendizaje de las culturas intersticiales: la pandilla sustituye a la familia, el gueto a la comunidad de origen, la casa de citas al hogar. Los espacios de reorganización social operan al margen de las instituciones. Si las instituciones del consenso normativo no resuelven las necesidades inmediatas, suena lógico actuar fuera de ellas. La escuela es reemplazada por una forma nueva de educación; ésta circula, no en las aulas, sino en el pavimento o en las esquinas de las urbes, a través de una suerte de currículo oculto. Y de éstas surge una suerte de solidaridad subterránea, necesaria en tiempo de crisis o de guerra. Felicidad transitoria, efímera. El encuentro callejero se transforma en convite, en un universo secreto que requiere de reglas y de aprendizaje. Fuera de este redil se está en el desamparo, en la orfandad social. Se requiere de una membrana protectora. Los inmigrantes simulan ser iguales, se identifican en una relación horizontal de precariedad, pero al mismo tiempo en el deseo incólume de superar esa situación y sobrevivir en los márgenes de sociedades nuevas. La felicidad aunque transitoria, les permite mantener la vigilia, el sueño. Todo se reduce a saber manejar las reglas del juego, respetar los roles y no traicionar. Uno de los mayores estigmas es el de la traición; conducta moralmente cuestionable. Si se traiciona al colectivo de origen, la acción amerita la expulsión o en áreas de formación de violencia, la muerte. El inmigrante de origen árabe, musulmán, o de Europa del Este, en el caso de Europa, es hoy en día, depositario de modernas formas de control social, destacando la selectividad étnica, y una política de recompensas basada en la delación de conductas sospechosas.

Planteado lo anterior, podemos entender el cambio de giro de la criminología estadounidense, uno de cuyos propósitos es reformar al desviado, y salvaguardar el ideologizado "crisol de razas" de la amenaza sin freno de los inmigrantes: los otros, los parias sociales. Arquetipo de los seres siniestros y peligrosos que alimentaron las fantasías literarias de autores como Lovecraft, el poeta del caos reptante, o las reflexiones de John Commons que ya en 1911 escribía: "Esta asombrosa criminalidad de los hijos de inmigrantes ( ... ) los muchachos, especialmente a edad temprana le pierden el respeto a sus padres, quienes no pueden hablar la lengua de la comunidad, y quienes son ignorantes e inútiles en el torbellino de la lucha por la existencia" (cfr. Zermeño, 1988:7). Ideas extremas, desde luego; no obstante, son parte del vocabulario cotidiano del candidato republicano, Donald Trump. En su opinión, los migrantes deben ser expulzados a como de lugar, pues constituyen la causa del declive económico de los Estados Unidos.

En la segunda década del nuevo siglo, tanto en Europa como en Estados Unidos, los inmigrantes siguen siendo vistos como sujetos amenazantes. Peligros de las grandes urbes; sinónimos de crimen y miseria. De ahí que el circuito punitivo encuentre en la selectividad actuarial, la herramienta básica de la moderna política criminal. Grandes temas del itinerario intelectual de las ciencias sociales cuyos campos de acción se despliegan en los 
territorios aún inasibles del mundo global: la incierta sociedad del riesgo de Beck, el Homo sacer de Agamben, o los presagios de la modernidad líquida anunciada por Zygmunt Bauman.

\title{
POLITICAL ECONOMY OF PUNISHMENT: DEVICES OF POWER AND SOCIAL CONTROL
}

\begin{abstract}
This essay aims at a transdisciplinary analysis of the political economy of punishment, focusing attention on the genealogy of "criminological knowledge", and the processes of constitution of the political devices of social control. The reflection is nourished with the theoretical collection of criminal law, criminology and anthropology, among other fundamental disciplines to understand the punitive coordinates of the contemporary world. Through these we reconstruct the ideological assumptions of the doctrine of social defense and, hypothetically, venture that the stigmatization of immigrant otherness in Europe and the United States, is supported by a reappraisal of normative devices that seemed to be overcome. Likewise, we have an analytical bridge between the knowledge of classical criminology and the reflections that support the modern stigmas of social control.
\end{abstract}

Keywords: Social stigma; social control; criminology; crime; immigrants.

\section{BIBLIOGRAFÍA}

BARATTA, Alessandro. Criminología crítica y crítica del derecho penal. Introducción a la sociología jurídicopenal. Buenos Aires: Siglo XXI, 2004.

BATAILLE, George, El límite de lo útil. Fragmentos de una versión abandonada de La parte maldita, Madrid: Losada, 2015

BAUMAN, Zygmunt. La modernidad líquida. México: Fondo de Cultura Económica, 2002.

BECCARIA, Cesare. De los delitos y las penas. México: Fondo de Cultura Económica, 2000.

CLASTRES, Pierre. Investigaciones en antropología política. Barcelona: Gedisa, 2013.

CORIAT, Benjamin. El taller y el cronómetro. Ensayo sobre el taylorismo, el fordismo y la producción en masa. México: Siglo XXI, 2011.

FOUCAULT, Michel. La verdad y las formas jurídicas. Barcelona: Gedisa, Barcelona, 2009.

La vida de los hombres infames. Ensayos sobre desviación y dominación, Madrid: Las Ediciones de La Piqueta, 1990.

Vigilar y castigar. Nacimiento de la prisión. México: Siglo XXI, 1997.

GAMBETTA, Diego. La mafia siciliana. El negocio de la protección privada. México: Fondo de Cultura Económica, 2007. 
GARCÍA, Carlos. Estudios de derecho penitenciario. Madrid: Tecnos, Madrid, 1982.

GOULDNER, Alvin. La crisis de la sociología occidental. Buenos Aires: Amorrortu, 2000.

HABERMAS, Jünger. Facticidad y validez. Madrid: Trotta, 2000.

HOBBES, Thomas. Leviatán. México: Fondo de Cultura Económica, 1990.

JACORZYNSKI, Witold. Estudios sobre la violencia. Teoría y práctica. México: Ciesas/Miguel Ángel Porrúa, México, 2002.

JULIANO, Dolores. Excluidas y marginales. Madrid: Cátedra, 2004.

KELSEN, Hans. ¿Qué es la teoría pura del derecho? México: Fontamara, México, 2012.

LAMNEK, Siegfried. Teorías de la criminalidad: una confrontación crítica. México: Siglo XXI, 2002.

LARRAURI, Elena. La herencia de la criminología crítica. México: Siglo XXI, 1992.

LUQUE, Enrique. Antropología política. Ensayos críticos, Barcelona: Ariel, 1996.

MACPHERSON, Crawford. La teoría política del individualismo posesivo. De Hobbes a Locke. Madrid: Trotta, 2005.

MAFFESOLI, Michel. El tiempo de las tribus. Barcelona: Icaria, 2004.

MELOSSI, Darío y Pavarini, Máximo. Cárcel y fábrica. Los orígenes del sistema penitenciario. México: Siglo XXI, 1981.

MEREU, Ítalo. Historia de la intolerancia en Europa. Barcelona: Paidós, Barcelona, 2003.

MORRIS, Brian. Introducción al estudio antropológico de la religión. Barcelona: Paidós, Barcelona, 1995.

MORRIS, Norval. El futuro de las prisiones, México: Siglo XXI, 1998.

PAVARINI, Massimo. Control y dominación. Teorías criminológicas burguesas y proyecto hegemónico. México: Siglo XXI, 2003.

PAYÁ, Víctor. Vida y muerte en la cárcel. Estudio sobre la situación institucional de los prisioneros. México: UNAM/Plaza y Valdés, 2006.

PEREYRA, Carlos. Breve historia de América. Santiago de Chile: Zig Zag, 1938.

SABINE, George. Historia de la teoría política. México: Fondo de Cultura Económica, México, 1984.

SUTHERLAND, Edwin. El delito de cuello blanco. Madrid: Ediciones de La Piqueta, Madrid, 1999.

Ladrones profesionales. Madrid: Ediciones de La Piqueta, 1993. 
TAYLOR, Ian y Paul Walton y Jock Young. La nueva criminología. Contribución a una teoría social de la conducta desviada. Buenos Aires: Amorrortu, 1997.

ZERMEÑO, Guillermo. EUA. Documentos de su historia socioeconómica, V. 7, México: Instituto Mora, 1988.

Trabalho enviado em 16 de abril de 2017.

Aceito em 25 de abril de 2017. 